\title{
Awareness of Dental Care amongst People Visiting Dentist
}

\author{
Bansari Rao ${ }^{1}$, Satish Kolte ${ }^{2}$ \\ Department of Chwmistry, Kishinchand Chellaram College Churchgate,Mumbai - 400020,India
}

\begin{abstract}
The study aims at awareness and ignorance of a common man towards oral hygiene in Mumbai. To evaluate awareness regarding oral hygiene practices a survey was conducted among 2000 people visiting a dentist. A structured questionnaire was used to collect information. Among various brands Colgate was found out to be the most popular toothpaste brand. $54.6 \%$ people do not know about the specialties of the toothpaste, $63 \%$ people are not aware about the expiry dates, $32.7 \%$ people have accepted a particular brand of toothpaste as a family brand blindly. Regarding to the oral health issues and habits $21.2 \%$ people have gum problems, $84 \%$ people do not go for regular dental check-up and inspite of using a particular brand of toothpaste people have dental problem. Along with the survey conducted 20 dentist were interviewed and the result were depicted that cavity and root canalling is the most prominent tooth problem and 75\% of the people have carefree response towards oral health. The statistical analysis of the survey was done with the help of "chi-square test" which indicates lack of awareness and complete ignorance of oral health amongst the common people in Mumbai. Oral health awareness and practices needs to improved for better approach towards sustainable health.
\end{abstract}

Keywords: oral health, awareness, dentist, ignorance, toothpaste, expiry dates

\section{Introduction}

Human beings have been anxious to clean their teeth as far back as we know but we have little information about the very early history of toothpaste. There are records showing that a Persian innovator in the ninth century manufactured some sort of tooth cleaning product which gained popularity, there are local testaments from the time which claim the product to be both functional and pleasant to taste.

Toothpaste is a soft substance that is used in the process of brushing teeth. Cleaning teeth means removing particles of food left over from eating and the plaque which is formed by the food. Plaque needs to be removed so that dental decay and gum disease cannot begin to take hold. Toothpaste also tends to be 'flavored' so that the user's breath is freshened after use and some help to aid in the whitening of teeth.

Fluoride is added to most toothpaste because of its properties of helping to strengthen the enamel of your teeth, which is first line of defence. If it is compromised, teeth might begin to decay as small holes or cavities are formed.

Detergent removes the food debris and plaque from the teeth and helps create fresh breath.

Abrasive too helps to remove debris and plaque. They also help to rid teeth of stains.

Humectants helps to keep the toothpaste adequately moist and of the desired texture. It is not active in the cleaning of teeth, it is added so that toothpaste can be stored for a long time and remain in the same, unstable state.

Thickener, is not an active ingredient; it just helps with the texture of toothpaste by making sure that the ingredients bind together properly.

Flavorings and Colorings are added to make individual toothpaste distinctive. This is often a branding issue and makes some people choose certain toothpastes over others. Certain flavorings might be added that actually have oral health benefits too, like some herbs which are associated with relieving gum disease. ${ }^{[1]}$

Earlier in India, oral hygiene was the domain of local homemade ayurvedic powders and natural herbs. Now, the awareness regarding oral hygiene in the Indian society has increased and thus many companies have come up with their brands of toothpaste. The first toothpaste to enter the Indian market was Colgate. In recent years the Industry has shown impressive growth rate of $18.6 \%$. Both the Gel and Cream segment of toothpaste industry are growing at a fast pace, particularly urban areas. Some of the most popular toothpaste brands in India are Colgate, Pepsodent, Close-up, Anchor, Aquafresh, Meswak, Vicco, Dabur, etc. ${ }^{[2]}$

\section{Literature Survey}

There have been various studies till now which have proved that there is a lack of awareness among the people related to oral health and hygiene. The study "Evaluating awareness regarding oral hygiene practices and exploring gender differences among patients attending for oral prophylaxis." By Oberoi SS1, Mohanty V2, Mahajan A2, Oberoi A3. States that The poor resources for dental care, common malpractices and non availability of professional care are the main barriers in seeking optimum oral hygiene [6]

Another study "Knowledge, attitude, and perception of mothers towards emergency management of dental trauma in Salem district, Tamil Nadu: a questionnaire study." By Murali K1, Krishnan R, Kumar VS, Shanmugam S, Rajasundharam P. reveals that there is a lack of awareness among the mothers regarding the emergency management of dental trauma. This warrants the need of an effective communication between dental professionals and mothers for better handling of dental emergencies. [7] 


\section{International Journal of Science and Research (IJSR) \\ ISSN (Online): 2319-7064 \\ Index Copernicus Value (2013): 6.14 | Impact Factor (2014): 5.611}

Study on" Awareness and Practices of Oral Hygiene and its Relation to Sociodemographic Factors among Patients attending the General Outpatient Department in a Tertiary Care Hospital of Kolkata, India." By Paul B, Basu M, Dutta S, Chattopadhyay S, Sinha D, Misra R also states that Oral health awareness and practices among the study population are poor and need to improve. [8]

Similarly study on "Knowledge, Attitude and Behaviour for Choosing Oral Hygiene Aids among Students ofManagement Institutes, Ghaziabad, India by Kote $\mathrm{S}^{1}$, Dadu $\mathrm{M}^{2}$, A R S $\mathrm{S}^{2}$, Ds $\mathrm{A}^{2}$, Arora $\mathrm{D}^{2}$.[9] And Survey on oral hygiene performance among dental patients in the Taiwan area. ByYao JH, Kao WJ.[10] States that due to a lack of knowledge and awareness about how to choose a dentifrice and toothbrush. and the dental health education on when to begin brushing a child's teeth. affects the oral health.

\section{Methodology}

\section{Questionnair Formulation}

In accordance to dental care and its awareness in the society the questionnaire was formed including which brand of toothpaste being used and daily regular habits and practice of one towards dental care.

\section{Sample Collection}

2000 people visiting dental care specialist were surveyed in western line of Mumbai, Questionnaire formed for the survey were filled by the people for analysis.

\section{Data Analysis}

All the data collected from the survey were analyzed with the help of chi-square test method.Chi-square is a statistical test commonly used to compare observed data with data we would expect to obtain according to a specific hypothesis. The formula for calculating chi-square $\left({ }^{2}\right)^{2}=(O-e)^{2} / e$

That is, chi-square is the sum of the squared difference between observed $(o)$ and the expected (e) data (or the deviation, $d$ ), divided by the expected data in all possible categories.

\section{Results and Discussion}

Which brand is used the highest?

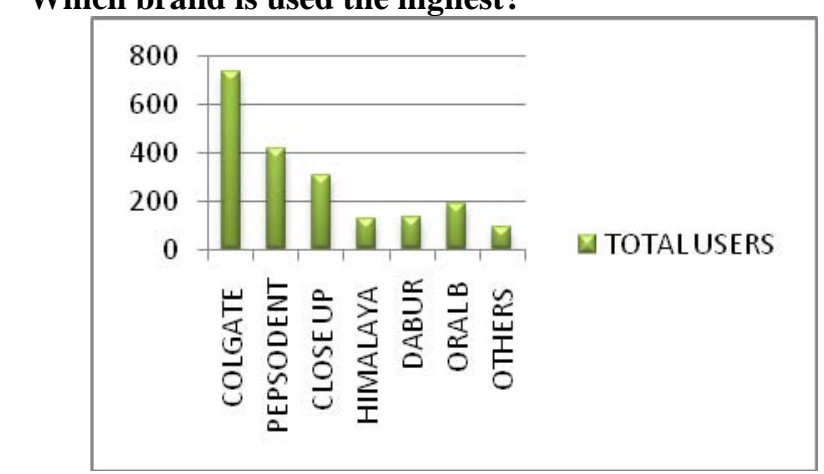

\section{Reason for purchasing a particular brand}

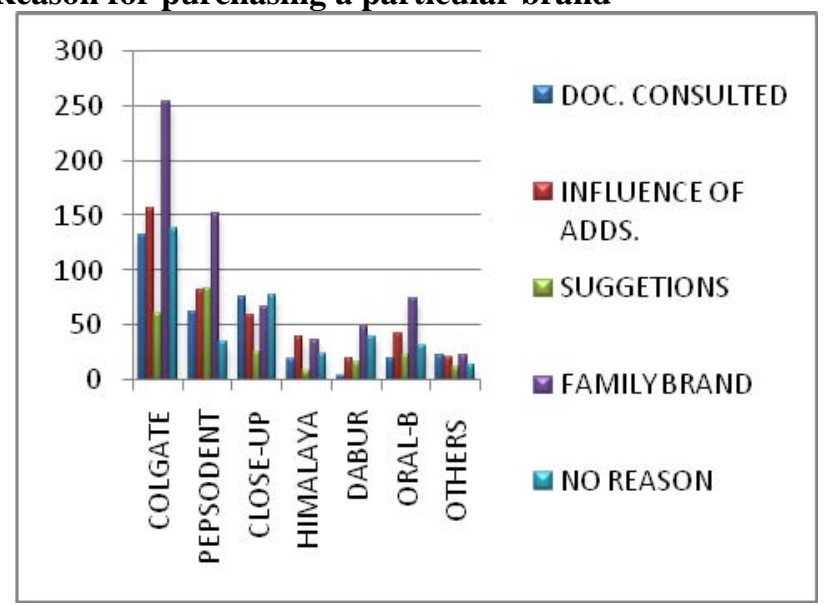

Most of the people use a particular brand of toothpaste cause of it being a family brand without knowing any specialty or importance of that particular brand. The second most reason for using a particular brand of toothpaste is due to influence of advertisement which means a person selects the brand of toothpaste on basis on various advertisement of a particular brand without considering the importance or speciality of that brand.

Are people aware about the speciality/expiry dates of the brand of toothpaste used

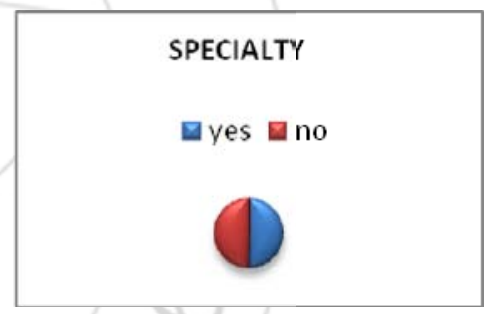

Out of the total population $54.6 \%$ of the people are not aware about the specialty of the particular brand being used by them which is almost the half of the population indicating that the people are using various brands of toothpaste without considering its importance or its effects.

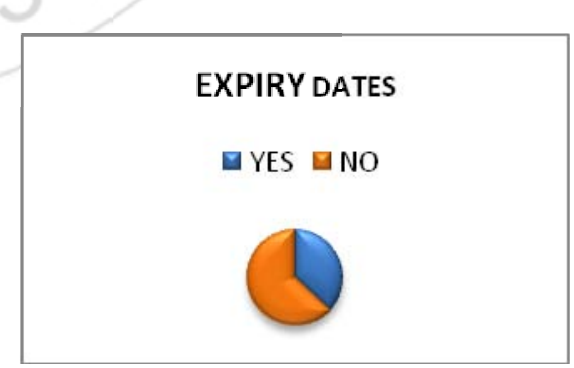

Out of the total population $63 \%$ of the people are not aware about the expiry dates which means people do not check expiry dates while purchasing the toothpaste. It indicates that the people are ignorant towards purchasing of toothpaste.

\section{Habits related to oral health}

Inspite of using a particular brand of toothpaste people still face the dental and oral problems which indicates that the 


\section{International Journal of Science and Research (IJSR) \\ ISSN (Online): 2319-7064 \\ Index Copernicus Value (2013): 6.14 | Impact Factor (2014): 5.611}

people are using a particular brand of toothpaste without knowing its specialty,importance or its after effects which is not helping them to overcome their problems People with habits such as eating/not eating sweet or fruit before bed and who consume or do not consume tobacco/tobacco products have dental problem which indicates that there is still some better advancements to be brought about in the production of thoothpaste or more awareness should be spread about the speciality of a particular brand of toothpaste and method of application of toothpaste should be improved and properly implemented

Do people go for regular dental check-up.

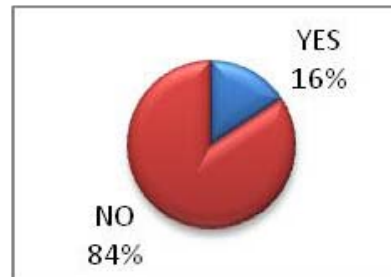

Out of the total population $84 \%$ of the people do not go for regular dental check-up which clearly indicates that the people are least bother towards their oral health.
Do you conduct any dental awareness camp/program or no?

\begin{tabular}{|l|l|}
\hline & Percentage \\
\hline Yes & $80 \%$ \\
\hline No & $20 \%$ \\
\hline
\end{tabular}

After the camp does people come back for further treatment suggested?

\begin{tabular}{|l|l|}
\hline & Percentage \\
\hline Yes & $45 \%$ \\
\hline No & $55 \%$ \\
\hline
\end{tabular}

\section{Conclusion}

- Total $37 \%$ of the population out of 2000 uses colgate.

- The second most reason for using a particular brand of toothpaste is due to influence of advertisement which means a person selects the brand of toothpaste on basis on various advertisement of a particular brand without considering the importance or speciality of that brand.

- Most of the people use a particular brand of toothpaste cause of it being a family brand .Means, one uses the same brand of toothpaste without knowing any speciality or importance of that particular brand.

- Out of the total population $54.6 \%$ of the people are not aware about the specialty of the particular brand .

- Out of the total population $63 \%$ of the people are not aware about the expiry dates. It indicates that the people are ignorant towards purchasing of toothpaste.

- Inspite of using a particular brand of toothpaste people still face the dental and oral problems which indicates people are using a particular brand of toothpaste without knowing its specialty,importance or its after effects which is not helping them to overcome their problemsPeople with habits such as eating/not eating sweet or fruit before bed and who consume or do not consume tobacco/tobacco products have dental problem which indicates that there is still some better advancements to be brought about in the production of thoothpaste or more awareness should be spread about the speciality of a particular brand of toothpaste and method of application of toothpaste should be improved and properly implemented

- Out of the total population $84 \%$ of the people do not go for regular dental check-up which clearly indicates that the people are least bother towards their oral health.

- Out of the total population $57 \%$ of the population brush only once a day. Hence it indicates that almost half the population is ignorant towards their oral health.

All the above points proves that there is a drastic ignorance towards dental care which indicates the need for more awareness programs to be conducted in order to create awareness about oral health amongst the common people, if people are more aware about oral health there would be a greater decrease in oral health problems.

\section{References}

[1] http://www.toothpaste.org.uk/what-is-the-history-oftoothpaste.html

[2] http://infobharti.com/indias-top-10/top-10-toothpastebrands-in-india.php 


\section{International Journal of Science and Research (IJSR) \\ ISSN (Online): 2319-7064 \\ Index Copernicus Value (2013): 6.14 | Impact Factor (2014): 5.611}

[3] http://www.buzzle.com/articles/ingredients-intoothpaste.html

[4] http://www.toothpaste.org.uk/what-is-the-history-oftoothpaste.html

[5] A knowledge, attitude, and practices study regarding dental floss among dentists in India. Madan $C^{1}$, Arora $\underline{\mathrm{K}}^{2}$, Chadha VS${ }^{2}$, Manjunath $\mathrm{BC}^{3}$, Chandrashekar $\mathrm{BR}^{4}$, Rama Moorthy $\mathrm{VR}^{5}$.

[6] Evaluating awareness regarding oral hygiene practices and exploring gender differencesamong patients attending for oral prophylaxis. $\underline{\text { Oberoi SS}}{ }^{1}$, Mohanty $\mathrm{V}^{2}$, Mahajan $\mathrm{A}^{2}$, Oberoi $\mathrm{A}^{3}$.

[7] Knowledge, attitude, and perception of motherstowardsemergencymanagement of dental trauma in Salemdistrict, TamilNadu: a questionnairestudy. Murali $\mathrm{K}^{1}$, Krishnan R, Kumar VS, Shanmugam S, Rajasundharam P.

[8] Awareness and Practices of Oral Hygiene and its Relation to Sociodemographic Factors among Patients attending the General Outpatient Department in a Tertiary Care Hospital of Kolkata, India. Paul B, Basu M, Dutta S, Chattopadhyay S, Sinha D, Misra R.

[9] Knowledge, Attitude and Behaviour for Choosing Oral Hygiene Aids among Students ofManagement Institutes, Ghaziabad, Indi. Kote $\mathrm{S}^{1}$, Dadu $\mathrm{M}^{2}, \underline{\mathrm{A} R \mathrm{~S}^{2}}$, Ds $\mathrm{A}^{2}$, Arora $\mathrm{D}^{2}$

[10] Survey on oral hygiene performance among dental patients in the Taiwan area. Yao JH, Kao WJ.

[11] Assessment of the awareness of dentalprofessionals regarding identification and management of dentalpatients with psychologicalproblems in routinedentaloperatory: a survey. Gupta $\mathrm{D}^{1}$, Sheikh S, Rashmi NC, Aggarwal A, Bansal R.

[12] A survey of rootcanaltreatment in SaudiArabia: a pilotstudy. Natto ZS.

[13]Attitudes and practices of infectioncontrol among seniordentalstudents at college of dentistry, university of Sharjah in the UnitedArabEmirates. Rahman $\mathrm{B}^{1}$, $\underline{\text { Abraham SB}}^{1}$, Alsalami $\mathrm{AM}^{2}$, Alkhaja FE ${ }^{2}, \underline{\text { Najem SI}}{ }^{2}$.

[14] Oralhealthsurvey and oralhealthquestionnaire for highschoolstudents in Tibet, China. $\underline{\operatorname{Hou} \mathrm{R}^{1}}, \underline{\mathrm{Mi} \mathrm{Y}}, \underline{\mathrm{Xu}}$ $\underline{\text { Q, Wu F}}, \underline{\text { Ma Y }}, \underline{\text { Xue P }}, \underline{\text { Xiao G}}$, Zhang Y $, \underline{\text { Wei Y }}, \underline{\text { Yang }}$ W.

[15] Is advertising by dentalprofessionals having a negativeimpact on consumers?: the perspectives of Indianconsumers. Dable RA ${ }^{1}$, Musani SI, Wasnik PB, Nagmode SL, Pawar BR.

[16] ToothpasteUtilizationProfiles among Preschool Children. Bennadi $\mathrm{D}^{1}$, Kshetrimayum $\mathrm{N}^{2}$, Sibyl $\mathrm{S}^{3}$, Reddy $\mathrm{CV}^{4}$.

[17] The miswak (chewingstick) and oralhealth.Studies on oralhygienepractices of urbanSaudiArabians. al-Otaibi M.

[18] Oral hygienehabits and oral healthawareness among urbanSaudiArabians. Al-Otaibi $\mathrm{M}^{1}$, Angmar-Månsson B.

[19] Use of miswakversustoothbrushes: oralhealthbeliefs and behaviours among a sample of Jordanianadults. Tubaishat $\mathrm{RS}^{1}$, Darby ML, Bauman DB, Box CE. district/Jordan. El-Qaderi SS $^{1}$, Taani DQ.

[20] Relationships between dietarybehaviours, oralhygiene and mutansstreptococci in dental plaque of a group of infants in southernEngland. Habibian $\mathrm{M}^{1}$, Beighton $\mathrm{D}$, Stevenson R, Lawson M, Roberts G.

[21] Dental healthhabits of 3-year-oldFinnishchildren.Paunio $\underline{\mathrm{P}}^{1}$, Rautava P, Sillanpää M, Kaleva O.

[22] Dentalhealthhabits of youngfamilies from southwesternFinland. Paunio P.

[23] Influence of mothers' oral healthknowledge and attitudes on their children'sdental health. SaiedMoallemi $\mathrm{Z}^{1}$, Virtanen JI, Ghofranipour F, Murtomaa $\underline{\mathrm{H}}$.

[24] Oralhealth of individualsaged3-80years in Jönköping, Sweden during 30years (1973-2003). I. Review of findings on dentalcarehabits and knowledge of oralhealth. Hugoson $\mathrm{A}^{1}$, Koch G, Göthberg C, Helkimo AN, Lundin SA, Norderyd O, Sjödin B, Sondell K.

[25] Comparativeeffect of chewingsticks and toothbrushing on plaqueremoval and gingivalhealth. Al-Otaibi $\mathrm{M}^{1}, \underline{\mathrm{Al}-}$ Harthy M, Söder B, Gustafsson A, Angmar-Månsson B.

[26] Prevailingoralhygienepractices among urbanSaudiArabians in relation to age, gender and socio-economicbackground. Al-Otaibi $\mathrm{M}^{1}$, Zimmerman M, Angmar-Månsson B.

[27]Education level, oral hygiene and smoking habits of an elderly Saudi population in Riyadh. Almas $\mathrm{K}^{1}$, alShammari B, al-Dukhyeel S.

[28] Oral hygiene, dietary pattern and smoking habits of Bedouin (nomadic Arabs) population inSaudi Arabia. $\underline{\text { Almas K}^{1}}$, al-Amri M, al-Eid A, al-Shahrani S.

\section{Author Profile}

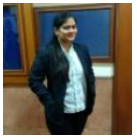

Bansari Rao is graduate in Bsc. Biotechnology Kishinchand Chellaram College, Mumbai ,Mumbai University, Maharashtra, India

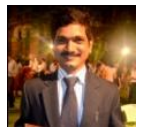

Dr. Satish Kolte is Phd in Chemistry Asst. prof. Department of chemistry at Kishinchand Chellaram college, Mumbai Mumbai University, Maharashtra, India Programme Officer of N.S.S. (National Service Scheme), Since 2004 he is District Coordinator of N.S.S., University of Mumbai, Since 2007 Research guide for M.Sc by Research and Ph,D in Chemistry. 